\title{
Excavaciones arqueológicas en el sitio de Buenavista (Lanzarote): nuevos datos para el estudio de la colonización protohistórica del archipiélago canario ${ }^{1}$
}

\author{
Pablo Atoche PeÑa \\ Universidad de Las Palmas de Gran Canaria. CEFYP \\ patoche@dch.ulpgc.es
}

\begin{abstract}
RESUMEN
Los trabajos arqueológicos desarrollados en el sitio de Buenavista (Lanzarote) han evidenciado la presencia de una amplia estructura constructiva de planta rectangular, inmersa en una secuencia estratigráfica en la que se ha registrado un numeroso contexto artefactual repartido en varias áreas funcionales y en un marco cronológico que discurre entre los siglos X a.C. y III d.C. Si ya de por sí esas fechas suponen una novedad con respecto a las cronologías que conocíamos para la Protohistoria canaria, no es menos novedoso el hecho de que se hayan obtenido de restos orgánicos asociados a diferentes registros materiales de procedencia cultural fenicio-púnica, en concreto cerámicas modeladas a torno, objetos fabricados en cobre y bronce o una cuenta vítrea. Este trabajo pretende dar a conocer una visión sintética de las intervenciones arqueológicas realizadas en Buenavista, efectuando una valoración general de los resultados más destacados a nivel estratigráfico, cronológico y del registro material.
\end{abstract}

Palabras clave: Islas Canarias, Protohistoria, Arqueología, colonización de islas, datación radiocarbónica.

Archaeological excavations in the Buenavista site (Lanzarote): New information for the study of the protohistoric colonization of the Canary Archipelago

\begin{abstract}
The archaeological works carried out at Buenavista (Lanzarote) have shown a big rectangular structure inside an stratigraphic sequence with a number of artifacts and chronology fluctuating between $10^{\text {th }}$ Century $\mathrm{BC}$ and $3^{\text {rd }}$ Century AD. The dates are new for Canarian protohistory, as well as the fact that organic remains associated to Phoeno-Punic materials (pottery, copper and bronze objects and a glass seed) have been found. The goal of this paper is to present a synthesis of the archaeological works at Buenavista showing stratigraphy, chronology and material record.
\end{abstract}

Key words: Canary Islands, Protohistory, Archaeology, islands colonization, radiocarbon dating.

1 Este trabajo se inscribe dentro de los estudios que estamos realizando en el marco del proyecto HAR2009-08519, “Canarias: colonización humana protohistórica, bioadaptación insular y transformación medioambiental”, financiado por el Ministerio de Ciencia e Innovación. IP: Pablo Atoche Peña. 


\section{Introducción}

La existencia de artefactos y otros elementos culturales de ascendencia fenicio-púnica en los contextos protohistóricos canarios no constituye una novedad contemporánea ya que han venido siendo puestos en evidencia en distintas publicaciones a lo largo del último siglo, si bien con una mayor frecuencia y aporte documental a partir de las últimas dos décadas (Balbín et alii, 1995; Atoche y Martín, 1999; Mederos y Escribano, 2002; González y Arco, 2007 y 2009). No obstante lo anterior, se hacía notar la carencia de asentamientos prolongados en el tiempo cuya antigüedad y contenidos materiales vinieran a refrendar no sólo la arribada de gentes fenicio-púnicas a las islas sino su más que probable participación en el proceso de colonización del archipiélago. La forma de llenar de contenido esa laguna en nuestro conocimiento fue efectuar extensas prospecciones, las cuales posibilitaron la localización de yacimientos que nos acercaron a las primeras etapas del poblamiento de las islas. En efecto, la puesta en marcha de esa labor en la isla de Lanzarote terminó por ponernos sobre la pista de un tipo de sitio arqueológico en el que se reproducía un particular patrón de asentamiento, lugares en los que inicialmente efectuamos excavaciones como El Bebedero (Teguise) y la Caldereta de Tinache (Tinajo), trabajos que aportaron los primeros datos en relación con la presencia en la isla de navegantes romanos y/o romanizados procedentes del Círculo del Estrecho entre los siglos I a.C. y IV d.C. (Atoche et alii, 1995). El inicio en el año 2006 de labores arqueológicas en un tercer lugar, el sitio de Buenavista (Teguise), terminaron por dar los resultados apetecidos produciéndose la exhumación de una amplia estructura constructiva de planta rectangular, inmersa en una secuencia estratigráfica en la que se ha registrado la presencia de un numeroso contexto artefactual repartido en diversas áreas funcionales y en un marco cronológico que discurre entre los siglos X a.C. y III d.C. Si ya de por sí las fechas anteriores suponen una novedad con respecto a las cronologías que poseemos para la Protohistoria canaria, no resulta menos novedoso el hecho de que esas dataciones se hubieran obtenido de restos orgánicos asociados a diferentes registros materiales de procedencia fenicio-púnica, en concreto fragmentos cerámicos modelados a torno pertenecientes a ánforas y otros elementos, varios objetos fabricados en cobre y bronce y una cuenta vítrea. Este trabajo pretende dar a conocer una visión sintética de las labores arqueológicas efectuadas en Buenavista y proceder a una valoración general de los resultados más destacados a nivel estratigráfico y cronológico.

\section{El yacimiento de Buenavista}

Buenavista se localiza en la región central de la isla de Lanzarote, a unos $8 \mathrm{~km}$ en línea recta de la costa norte, con una excelente visión sobre los Riscos de Famara y el Archipiélago Chinijo, elementos geográficos que conforman el brazo de mar denominado El Río, uno de los puertos naturales más aptos de Canarias y, por tanto, de la costa noroccidental africana (Fig. 1).

El sitio arqueológico se sitúa en el extremo oriental de una hondonada que discurre en sentido este-oeste, entre la cota de los 230 m.s.n.m. en el extremo occidental, área 
baja y cóncava donde suele formarse un depósito de agua estacional, y la cota de los 239 m.s.n.m. en el borde oriental, desde donde desciende una suave pendiente que conecta el lugar con las llanuras de El Jable a una cota de 226 m.s.n.m. La cuenca endorreica se encuentra delimitada tanto al norte como al sur por peñas que no superan los 250 m.s.n.m. en la vertiente septentrional, y los 270 m.s.n.m. en la meridional. En esencia, el yacimiento ocupa un espacio enclavado en la línea de contacto entre los fértiles suelos marrones del centro de la isla y las arenas de El Jable que la atraviesan de norte a sur, en un lugar cuyo aspecto y morfología son similares a los que muestran la Caldereta de Tinache (Atoche et alii, 2007) o la cercana cuenca en la que se localiza el yacimiento de El Bebedero (Atoche et alii, 1989). En los tres sitios se repite el mismo patrón de localización: fisonomía cerrada de cuenca u hoya protegida de los vientos dominantes, presencia de potentes suelos aluviales ricos en materia orgánica que le otorgan a esos parajes una alta fertilidad desde el punto de vista agrícola y un notable potencial de cara a su uso ganadero (Atoche, 1993). Debido a esas positivas características, no resulta extraño que a partir de la segunda mitad del siglo XX Buenavista pasara a formar parte de una extensa explotación agraria, cubriéndose por entonces el lugar con enarenados en los que inicialmente se cultivó tabaco y más tarde cereales (trigo y cebada) asociados con la vid. El abandono que ha sufrido el lugar durante las cuatro últimas décadas ha dado como resultado que las únicas huellas visibles que restan en la actualidad de su antigua función agrícola sean los viejos enarenados y los muretes, en muchos casos caídos, que delimitan los añejos sarmientos.

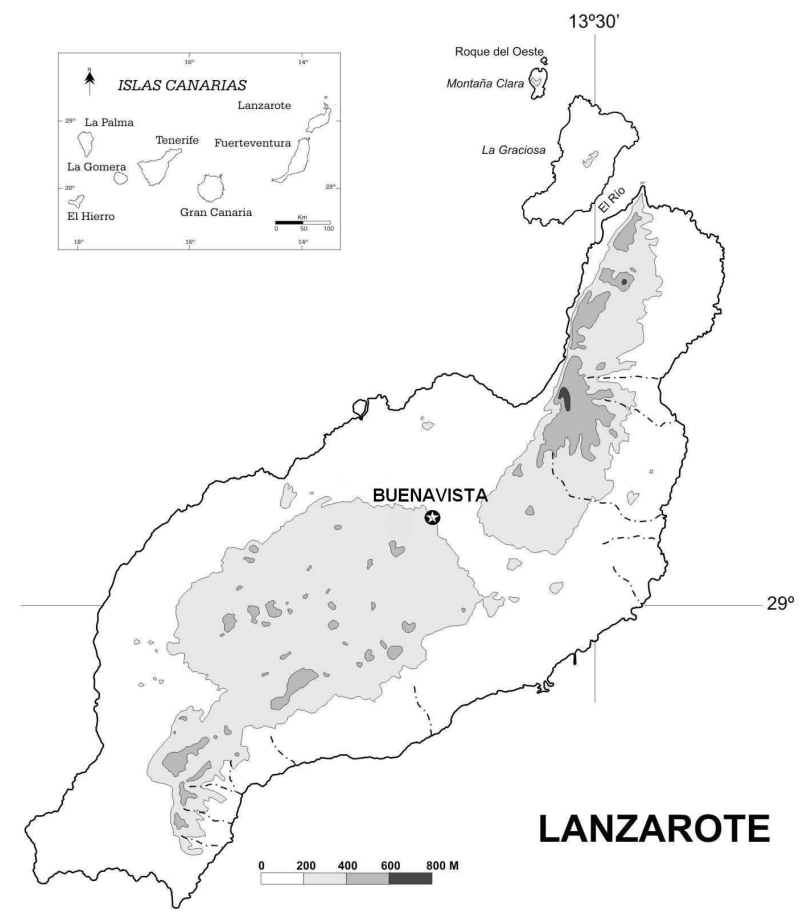

Fig. 1: Lanzarote (Islas Canarias). Localización del yacimiento de Buenavista. 
El yacimiento arqueológico de Buenavista se evidenció durante una extracción de rofe que, en la década de los años 70' del pasado siglo, afectó al edificio volcánico que por el este soporta y delimita la hondonada donde se encuentra el yacimiento, trabajos que al tiempo que revelaron la estructura interna del subsuelo también seccionaron parte del relleno sedimentario que lo cubría. Como resultado apareció un perfil estratigráfico de unos $50 \mathrm{~cm}$ de potencia arqueológica fértil, el cual se encontraba asentado sobre una base volcánica encalichada y cubierto por dos capas de rofe colocadas en el lugar para implantar el enarenado.

En 1994 Buenavista se inventarió en la Carta Arqueológica de Lanzarote con el número de identificación 69/6/0035 (Atoche, 1996), formando parte por su ubicación de un área más extensa, el Complejo Arqueológico de Tiagua, constituida por diversos asentamientos que, en su conjunto y a lo largo de dos milenios, captaron recursos de un territorio de explotación asentado sobre una misma unidad de acogida definida por la presencia de suelos marrones limitados en su extremo septentrional por las arenas de El Jable.

\section{Las labores de excavación arqueológica}

Entre los años 2006 y 2009 hemos desarrollado cuatro campañas de excavaciones, interviniendo en tres zonas diferentes de Buenavista mediante la puesta en práctica de una estrategia de área abierta (Lám. I); en total se han activado 84 cortes estratigráficos de 1x1 m de lado, localizándose la mayor parte de ellos en la zona donde apareció la estructura arquitectónica. El procedimiento de extracción del relleno sedimentario se ajustó en todo momento a la naturaleza del suelo y a las particularidades del yacimiento, viéndose inicialmente facilitada la excavación al contar con la referencia que suponía la presencia del perfil descubierto por las antiguas extracciones de arena. De forma general, la apertura de cada corte requirió la retirada previa de la gruesa capa superficial de rofe que cubre la totalidad de la hoya; se trata de un estrato artificial estéril de aproximadamente unos $20 \mathrm{~cm}$ de potencia, depositado hace unas dos décadas con la finalidad de rejuvenecer otra capa de rofe preexistente colocada sobre el suelo natural en la década de los años 40' del pasado siglo XX. Por tanto, una vez retirada la primera capa de rofe aparecía una segunda de polvillo o rofe antiguo, la cual constituía otro estrato artificial, al que en nuestro análisis estratigráfico le hemos adjudicado la denominación de estrato superficial y cuya colocación en el lugar fosilizó las capas arqueológicas subyacentes. Los restantes estratos se extrajeron respetando sus contornos y dimensiones naturales mediante niveles artificiales o subestratos de aproximadamente $10 \mathrm{~cm}$ de potencia, si bien la profundidad de éstos se ajustó en todo momento a la morfología de la estratificación del yacimiento con el fin de evitar la mezcla del contenido de los diferentes estratos y poder efectuar una correcta reconstrucción del orden secuencial de deposición. Tras la extracción de cada subestrato se procedió a la nivelación del sedimento y a su documentación. En suma, el estrato superficial se extrajo siempre de una sola vez, mientras que en el estrato I se delimitaron dos subestratos, denominados subestratos I-1 y I-2, y en el estrato II se delimitaron tres subestratos, denominados subestratos II-1, II-2 y II-3. Con esta estra- 
tegia conseguíamos mantener agrupados por estratos los registros materiales recuperados, permitiéndonos su repartición en subestratos observar cualquier variación que se hubiera producido a nivel de los contenidos o las características de esos registros.

Si bien la excavación en área abierta, sin la reserva de testigos, plantea el problema de documentar la diacronía, es decir la sección vertical, en nuestro caso la cuestión se ha solventado mediante el control periódico y la representación gráfica de diferentes perfiles estratigráficos en el sentido de los ejes N-S y E-W; de esa manera la adición de las sucesivas secciones documentadas nos permite obtener un perfil acumulativo que recorre la práctica totalidad de los dos ejes principales del yacimiento.

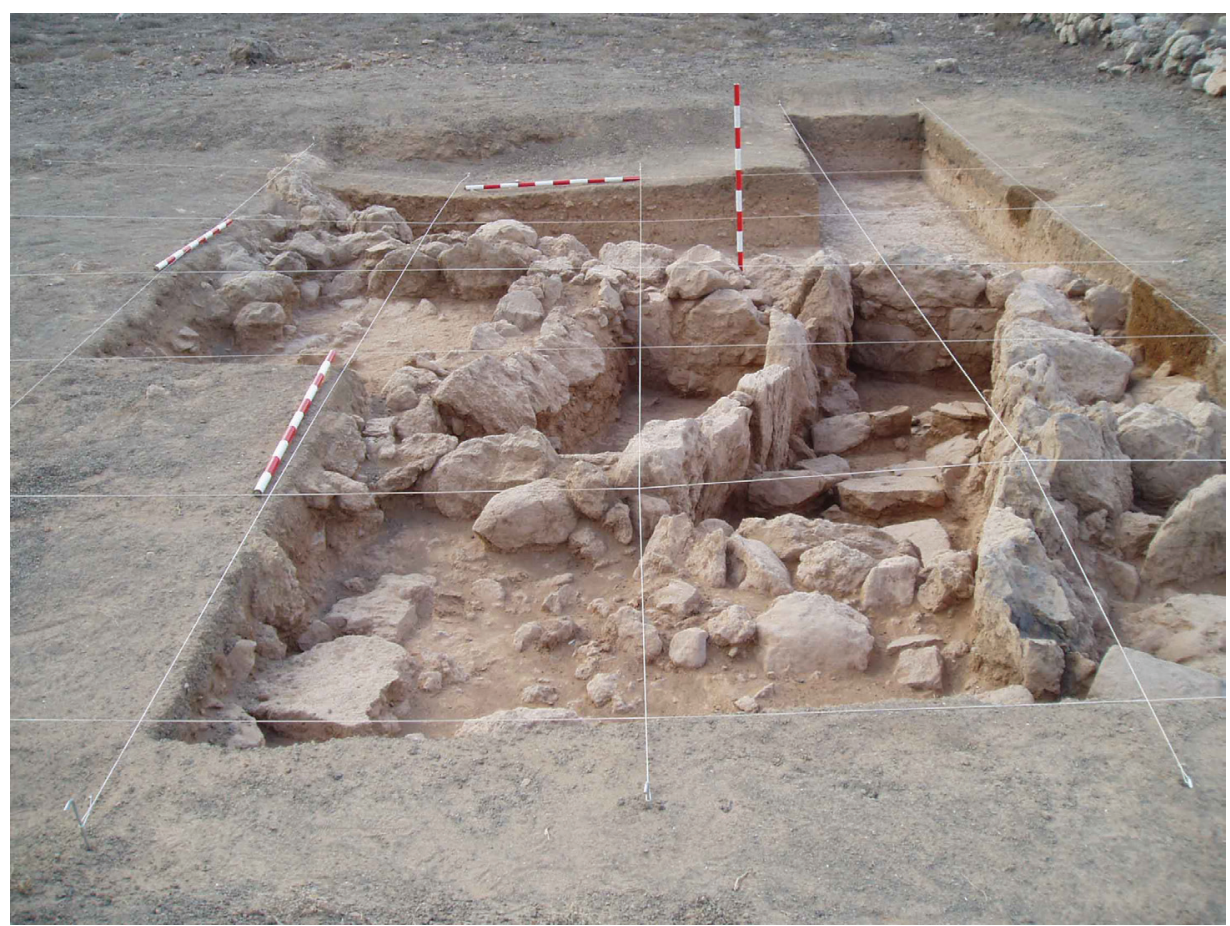

Lám. I: Buenavista. Área trabajada durante la primera campaña de excavaciones (año 2006)

En la excavación el orden de apertura de los cortes se inició por las cuadrículas A1, A2, A3 y A4, mostrándose ya en el estrato I un fragmento de muro de aparejo irregular seco, sin argamasa, con doble paramento relleno de ripios y tierra, el cual se asentaba casi directamente sobre la roca base y describía una ligera curvatura abierta hacia el sur. La aparición de ese elemento estructural vino a determinar el posterior desarrollo de la excavación, al señalarnos las cuadrículas que debían ser activadas a continuación. De esa manera durante la primera campaña la excavación fue extendiéndose en dirección sur y oeste (Atoche et alii, 2009), para durante la segunda 
campaña centrarse las tareas en el extremo occidental, en la tercera delimitarse los extremos sur y oeste de la estructura y en la cuarta campaña culminar algunas tareas en el interior de la estructura, además de proceder a la apertura de varios cortes en diferentes zonas de la hondonada, con la finalidad de calibrar la extensión total del yacimiento y la posible presencia de nuevas estructuras u otros elementos arqueológicos en el lugar. Como resultado de ese trabajo, a medida que se iban desarrollando las campañas de excavación se fue completando la extracción de una estructura de planta rectangular subdividida a su vez en varios habitáculos con diferentes morfologías y dimensiones. Al mismo tiempo se hizo patente la existencia de una secuencia estratigráfica en cuyo proceso de desarrollo era posible observar algunos comportamientos diferenciales según nos halláramos en el interior o el exterior de la estructura.

\section{La secuencia estratigráfica}

En Buenavista hemos podido delimitar una nueva secuencia crono-estratigráfica, la cual viene a sumarse a las que previamente exhumamos en El Bebedero (Atoche et alii, 1989) y la Caldereta de Tinache (Atoche et alii, 2007), con las que posee notables analogías, viniendo a complementar la secuenciación diacrónica que se ha establecido para la isla de Lanzarote (Atoche, 2008; Atoche, 2009).

La secuencia estratigráfica de Buenavista es muy estable, siendo posible identificar algunas diferencias en el proceso de sedimentación que siguió según se trate de la zona exterior o la interior de la estructura, lo cual constituye un aspecto a tener en cuenta de cara a la correcta interpretación arqueológica del sitio. De forma general se han documentado cuatro discontinuidades estratigráficas determinadas tanto por el color como por la textura y composición de los sedimentos; su desarrollo, si seguimos el mismo orden en el que se depositaron, sería el siguiente (Fig. 2):

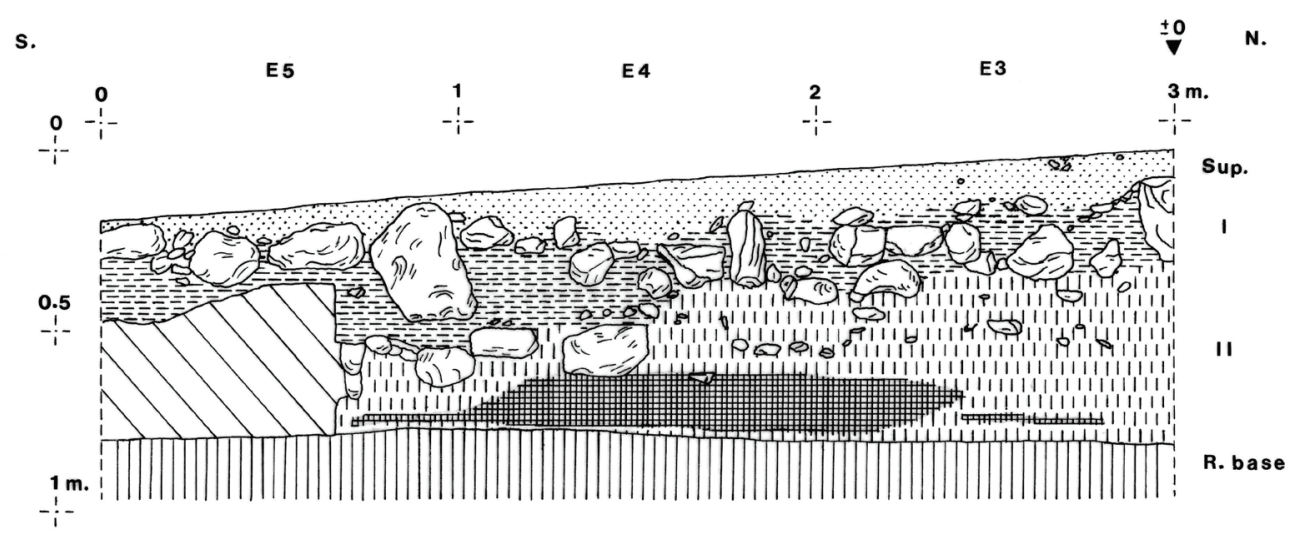

Fig. 2: Buenavista. Secuencia estratigráfica. Perfil oeste de los cortes E3, E4 y E5 
Roca base. Formada por un suelo encalichado o costra calcárea adosada al suelo volcánico, la cual reviste la ladera del edificio volcánico en la que se estableció el asentamiento humano. El soporte geológico sobre el que se desarrolló la costra está conformado por basaltos de la Serie III, la cual se diferencia de las otras series volcánicas definidas en la isla por el mayor grado de conservación de sus estructuras volcánicas y por un menor desarrollo de la costra caliza.

Los autores de la estructura constructiva procedieron a excavar el suelo calcáreo en el interior de la estructura hasta que alcanzaron una cota de $0.40 \mathrm{~m}$ por debajo del nivel original; la superficie así obtenida se regularizó y consolidó cubriéndola con una ligera capa de arcilla rojiza apisonada.

Estrato II. De coloración marrón muy pálido (10YR-7/3) (Munsell, 1975), presenta una textura muy homogénea, arcillosa, con una granulometría que denota su constitución en un ambiente caracterizado por una notable fitoestabilidad. Este estrato constituía el suelo original que se encontraron los primeros ocupantes del lugar. Presenta un desarrollo muy homogéneo, asentándose en él los muros de la estructura; sus características, en cuanto a composición, coloración y textura, son similares a las que presenta el estrato V tanto de El Bebedero como de la Caldereta de Tinache. Dentro de las clases agrológicas definidas en la isla de Lanzarote (Marcos, 1986: 57 y ss.; Hernández et alii, 1991), este suelo se corresponde con la Clase III, más concretamente con la subclase IIIc, probablemente la mejor representada a nivel insular, la cual suele localizarse en zonas con topografía muy suave, con pendientes inferiores al $10 \%$, sin problemas de tipo edáfico al ser suelos potentes, textura equilibrada, con contenido en materia orgánica y un importante porcentaje de arcilla, lo que les permite una buena retención del agua. Son, en definitiva, los denominados suelos marrones o fersialíticos conocidos en la isla bajo la denominación popular de tierra bermeja debido a su notable coloración rojiza y que poseen como principal limitación las condiciones climáticas de gran aridez que se dan en la isla, lo que unido a la inexistencia de regadíos ha propiciado que para mejorar su rendimiento agrícola se haya tendido a recubrir con capas de cenizas basálticas de aproximadamente $20 \mathrm{~cm}$ de potencia ${ }^{2}$.

Estrato I. De aspecto muy compacto, color marrón (7.5YR-5/4) y textura franco-limosa en la que se insertan numerosas rocas de diferentes tamaños repartidas irregularmente sobre todo a lo largo del tercio superior del estrato. Esta unidad sedimentológica se corresponde con un episodio de destrucción que en El Bebedero y la Caldereta de Tinache se identificó a partir del estrato IV. Tiene un neto carácter antrópico; su morfogénesis es indicativa de la pasada existencia de un aceleramiento de la erosión de los suelos que cubrían las laderas circundantes de la hondonada, reflejando una situación que aconteció en general en toda la isla a partir del siglo I a.C., cuando

2 La utilización de cenizas basálticas (denominadas arenas, de ahí el nombre de enarenados que recibe este tipo de cultivos) se ha generalizado en toda la isla con el fin de posibilitar la práctica de un cierto tipo de agricultura, ya que al situarse sobre la superficie del suelo permite que éste mantenga la humedad de manera casi constante, evitando la evaporación. Al mismo tiempo también actúan regulando la temperatura del suelo y como protectoras frente a la acción del viento, evitando la pérdida de la fracción fina. Se aprovechan así los altos valores de la humedad relativa existente en la isla, la cual es fácilmente absorbida por las cenizas, pasando al suelo subyacente de forma que aquél se mantiene húmedo casi todo el año, permitiendo un tipo de agricultura original y propio de Lanzarote. 
el paisaje de Lanzarote estuvo sometido a un considerable incremento de la energía cinética como resultado de la destrucción de la cobertura vegetal. Las pendientes sufrirían una pérdida rápida de vegetación debido al sobrepastoreo de cabras y ovejas, lo que causaría la exposición de los suelos a la acción erosiva de la lluvia facilitando el arrastre de elementos cada vez más gruesos, como muestran las rocas que tapizan el estrato I (Atoche, 2003; Criado y Atoche, 2003).

Estrato superficial. Constituido por una capa de rofe de granulometría muy regular (entre 0.5 y $1 \mathrm{~cm}$ ) y color gris $(10 \mathrm{YR}-5 / 1)$ que se colocó directamente sobre el suelo preexistente en la década de los años 40' del siglo XX con la finalidad de mejorar su fertilidad; se formó así un suelo agrícola artificial (enarenado) que fosilizó los niveles arqueológicos subyacentes. Mientras que en sitios como El Bebedero o la Caldereta de Tinache se procedió a la construcción de auténticos enarenados, en Buenavista éste no lo es en sentido estricto, es decir, creado por el depósito sucesivo de tres estratos (arena, tierra vegetal y rofe), ya que a ese lugar no se transportaron sedimentos ricos para preparar el suelo agrícola sino que se aprovechó el suelo preexistente (el estrato I), el cual simplemente se cubrió con una potente capa de rofe (el estrato superficial).

\section{Los registros materiales}

Los elementos arqueológicos recuperados en Buenavista se reparten básicamente en tres categorías: elementos estructurales, artefactos materiales y elementos faunísticos. A continuación analizaremos algunos de los hallazgos más destacados pertenecientes a las dos primeras categorías en atención a su alto valor diagnóstico.

\subsection{Los elementos estructurales}

La estructura exhumada presenta una planta rectangular (Fig. 3), ocupando una superficie aproximada de $42 \mathrm{~m}^{2}$. Está constituida por un muro exterior de piedra seca de entre 0.70 y $0.85 \mathrm{~m}$ de espesor ${ }^{3}$, el cual encierra a su vez paredes bajas de menor grosor (de entre 0.22 y $0.50 \mathrm{~m}$ ) que delimitan tres recintos alargados y estrechos, de planta rectangular (con $2.70 \times 0.86 \mathrm{~m}, 2.08 \times 0.72 \mathrm{~m}$ y $1 \times 0.43 \mathrm{~m}$ respectivamente), cuyos suelos se encuentran a unos $0.40 \mathrm{~m}$ por debajo de la cota exterior de la roca base, hallándose recubiertos por un sedimento rojizo bien consolidado. El recinto de mayores dimensiones, adosado al muro oriental, contenía en el momento de su exhumación un nivel de abandono que fue datado en el siglo IV a.C. y en el que se registraron diferentes artefactos in situ (Lám. II). Además de esos recintos, en los ex-

${ }^{3}$ El codo grande púnico medía alrededor de $52 \mathrm{~cm}$, mientras que el codo pequeño tenía alrededor de $44 \mathrm{~cm}$. En Ibiza el codo pequeño se utilizó como medida para paredes medianeras, mientras que el codo y el codo pequeño y medio se emplearon tanto para subdivisiones como para muros exteriores (DíES Y Matamoros, 1991: 821).

4 Entre los registros recuperados sobresalen una amplia estela lítica trapezoidal con motivos esquemáticos grabados en una de sus caras, varios recipientes fragmentados de gran tamaño, la piedra durmiente de un molino circular y diversos elementos líticos de compleja interpretación. En este nivel 
tremos sur y oeste de la estructura se encuentran dos habitaciones cuadrangulares (de aprox. 4 y $7 \mathrm{~m}^{2}$ respectivamente), la segunda de ellas abierta hacia el exterior donde se comunica con un amplio espacio circular (de aprox. $6 \mathrm{~m}^{2}$ ) bien protegido de los vientos dominantes por sus extremos norte y oeste mediante un muro alto y grueso, mientras que el resto de su desarrollo está delimitado por una alineación de rocas bajas hincadas en el suelo, las cuales describen un semicírculo casi perfecto. Estos dos últimos espacios encerraban un potente estrato II, el cual contenía abundantes sedimentos orgánicos (cenizas) asociados a varias estructuras de combustión; de aquí se obtuvieron dos dataciones $\mathrm{C}^{14}$. Adosado a lo largo del extremo interior del muro oeste se encuentra un banco bajo de piedra construido siguiendo las mismas técnicas que el resto de la estructura.

El material constructivo utilizado en la estructura fue la roca volcánica local (basaltos), de tamaños variables, empleándose algunas piedras de dimensiones superiores a los $0.50 \mathrm{~m}$ de largo, aprovechándose las caras planas sin que hayan sido aparentemente trabajadas. Rocas de menor tamaño se usaron como cuñas entre los bloques o para rellenar el interior de los muros. La técnica de traba fue la arcilla bajo la forma de un relleno de tierra y ripios, consiguiendo darle así consistencia al muro.

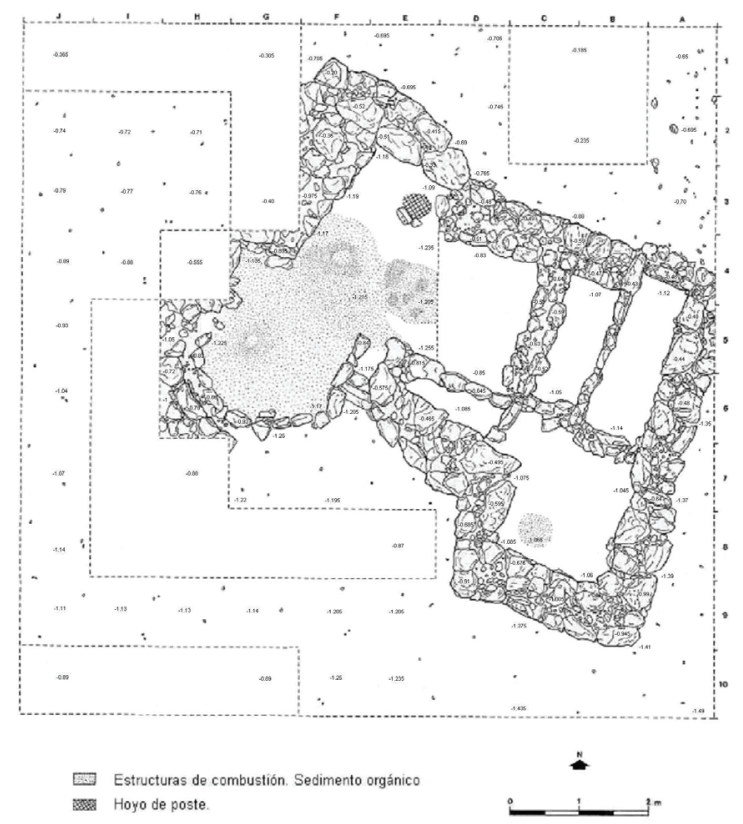

Fig. 3: Buenavista. Planta general de la estructura constructiva

de abandono también se registró la presencia de restos de sedimentos orgánicos (cenizas), de los que se tomaron muestras para proceder a su análisis y datación radiocarbónica. En el segundo recinto igualmente se evidenció el mismo nivel de abandono, si bien los artefactos que contenía eran menos numerosos, tratándose sólo de fragmentos cerámicos, en algún caso perteneciente a uno de los vasos hallados en el primer recinto, además de un elemento lítico con superficies pulimentadas. 
La técnica empleada para levantar los paramentos fue doble; mientras que los muros exteriores se construyeron por medio de dos hiladas de rocas con relleno de tierra y ripios, los tabiques que delimitan los recintos internos se realizaron con lajas hincadas en el suelo. En ambos casos los muros se asentaron directamente sobre el suelo (la base del estrato II) o sobre la roca base, siendo inexistente la cimentación. El suelo interior, excavado unos $0.40 \mathrm{~m}$ por debajo del nivel exterior, está constituido por una fina capa de tierra rojiza batida colocada sobre la roca base; se encuentra más o menos nivelado, aunque en el recinto oriental presenta un desnivel de casi $10 \mathrm{~cm}$ en sólo $3 \mathrm{~m}$.

No se ha registrado la presencia de restos de materiales perecederos (madera,...), pero sin duda éstos debieron formar parte de la construcción, especialmente en la cubierta.

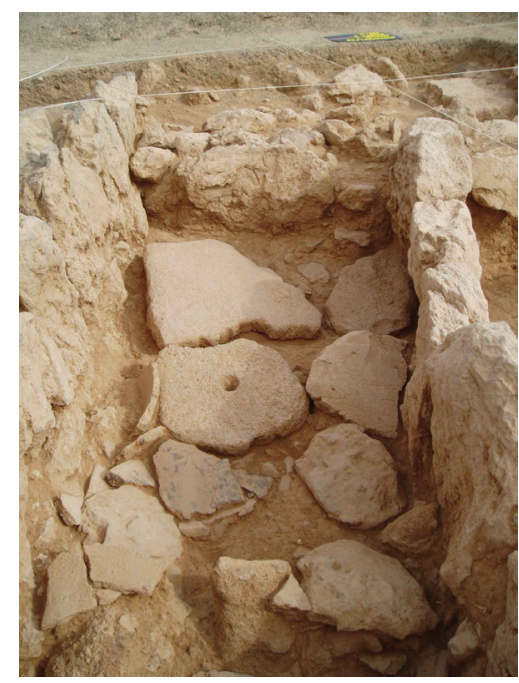

Lám. II: Buenavista. Artefactos localizados in situ en el habitáculo n ${ }^{0} 1$

En el ámbito cultural púnico hay claras diferencias entre el hábitat rural y el urbano (Díes y Matamoros, 1991). Así, mientras en el segundo se pusieron en práctica unas técnicas constructivas más depuradas (muros trabajados, paredes cubiertas de arcilla,...), en los asentamientos rurales, como parece ocurrir en el caso de Buenavista, se trata de sitios con unas dimensiones más reducidas, encontrándose asociados a una actividad económica concreta, la explotación de recursos agrarios. En este último caso las estructuras constructivas son bastante toscas ya que las rocas rara vez se han canteado, siendo la técnica de traba siempre la arcilla, con escasos revestimientos, por lo general muy groseros. Los suelos son de tierra batida y no existen las cimentaciones o éstas son someras. Su reducido tamaño suele deberse a que se trata de lugares que fueron habitados por grupos familiares pequeños, simples asentamientos destinados a la explotación agrícola. 


\subsection{Las cerámicas modeladas a torno}

Se han recuperado casi cincuenta fragmentos de cerámicas modeladas a torno (Lám. III), los cuales proceden mayoritariamente del estrato I de los cortes abiertos en el exterior de la estructura constructiva. Los fragmentos a torno recuperados en el interior del recinto proceden del estrato II, concentrados mayoritariamente en el sector occidental, donde se hallaban inmersos en una extensa estructura de combustión compuesta por tres hogares. También apareció un número significativo de fragmentos en el interior del recinto oriental asociados al nivel de abandono del estrato II. De una manera general, y desde la perspectiva estratigráfica, los hallazgos de cerámicas a torno se reparten de la siguiente manera:

- Estrato II-3: Dos fragmentos amorfos, en ambos casos con un engobe amarillo rojizo. Uno de estos fragmentos fue seleccionado con destino a los análisis petrológicos (muestra $\mathrm{n}^{\mathrm{o}} 6$ ).

- Estrato II-2: Dos fragmentos amorfos, uno de superficie amarillo rojiza y el otro de pared muy gruesa y pasta roja; este último se seleccionó para la analítica petrológica (muestra $\mathrm{n}^{\mathrm{o}} 1$ ).

- Estrato II-1: Siete fragmentos, de los que dos pertenecen a la pared de un ánfora con estrías marcadas y superficie exterior de color amarillo rojizo; ambos fueron seleccionados para la analítica petrológica (muestras $n^{\circ} 9$ y 10). Los restantes fragmentos son de pequeño tamaño, algunos auténticas esquirlas; uno de ellos corresponde a un recipiente modelado a torno lento. Presentan coloraciones rosa y rojo amarillento.

- Estrato I-2: Diez fragmentos (en algún caso sólo esquirlas) mayoritariamente amorfos excepto en un caso correspondiente a la boca de un ánfora púnica, de pasta rojiza con engobe de color beige, a la que se ha podido identificar ${ }^{5}$ con la forma Mañá $\mathrm{D}^{6}$. En el resto de los casos se trata de pastas de color rojizo, en ocasiones con engobe de color beige. De este grupo se seleccionaron varios fragmentos para la analítica petrológica, en concreto uno de superficie de color rosa (muestra $\mathrm{n}^{\circ} 7$ ), un segundo amorfo de superficie amarillo rojiza con estrías marcadas, cocción irregular, superficies de escasa calidad y corazón oscuro (muestra $n^{\circ} 2$ ); un tercer fragmento, también amorfo, con la superficie amarillo rojiza y estrías anchas (muestra $\mathrm{n}^{\circ} 5$ ). Una última muestra corresponde a un fragmento de borde perteneciente a un pequeño cuenco semiesférico modelado a torno lento (muestra $n^{\circ} 3$ ).

- Estrato I-1: Trece fragmentos, en todos los casos procedentes de cortes abiertos en el exterior de la estructura. Salvo en cuatro casos se trata de fragmentos amorfos con pastas rojizas, algunos con paredes gruesas y otros con engobes de color beige. Junto a los anteriores hay cuatro fragmentos cerámicos que presentan alguna particularidad formal que permite una mayor aproximación a su caracterización cultural. En un caso se trata de un fragmento de la contera de un ánfora

${ }^{5}$ La identificación tipológica de esta pieza se la debemos a Mariano Torres de la Universidad Complutense de Madrid.

${ }^{6}$ En Mogador también se conoce otro fragmento del mismo tipo de ánfora (LóPEZ y MEDEROS, 2008: 198). 
de pasta muy fina y color rojizo; un segundo fragmento corresponde al cuerpo de un ánfora, de superficie exterior rojiza con estrías muy marcadas y un diámetro aproximado de $25 \mathrm{~cm}$; se trata posiblemente de un ánfora del tipo Cádiz A4 (ss. II-I a.C.). Un tercer fragmento, también de pared de ánfora y pasta rojiza presenta en la superficie exterior estrías gruesas. Por último, el cuarto fragmento corresponde al borde redondeado de una terracota de pasta rojiza del estilo de las pequeñas figuras votivas del sur de la Península Ibérica o Baleares.

- Estrato superficial: Doce fragmentos caracterizados en su mayor parte por presentar una o las dos superficies vidriadas (verde, beige,...); uno de ellos pertenece a un fragmento de plato de porcelana y otro a una anforeta del siglo XIX. De este grupo se tomó una muestra para análisis petrológico (muestra $\mathrm{n}^{\circ} 4$ ).

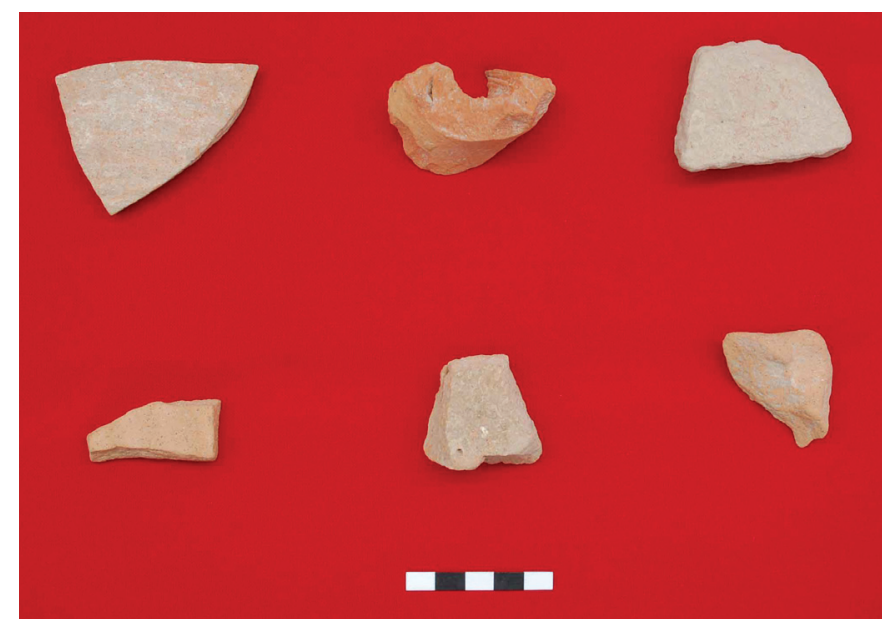

Lám. III: Buenavista. Algunos de los fragmentos cerámicos modelados a torno hallados en el yacimiento

Como puede observarse de la relación anterior, la muestra seleccionada para los análisis petrológicos estaba constituida por nueve fragmentos cerámicos modelados a torno, los cuales fueron enviados a la Universidad de Zaragoza, donde Ion Ander Somovilla de Miguel y Josep Gisbert Aguilar, se encargaron de llevar a cabo su caracterización macroscópica, la caracterización petrológica al microscopio petrográfico mediante la observación de láminas delgadas y la comparación de las piezas con el fin de agruparlas en conjuntos de características similares; finalmente, se realizó una aproximación a la identificación de procedencia de las materias primas que componen las piezas. La técnica empleada en la caracterización petrológica de las muestras (petrografía óptica de luz transmitida) se basa en el estudio de una lámina delgada (30 $\mu \mathrm{m}$ de espesor) mediante un microscopio petrográfico. Se obtiene así una visión en detalle de la composición de la muestra, además de la disposición de los diferentes elementos texturales que la componen (pasta, desgrasante y porosidad). Para la caracterización macroscópica se ha realizado una inspección visual de las piezas, con 
la ayuda de una lupa binocular. Con esta técnica se caracteriza el color, la disposición de los componentes de la muestra y el tamaño de los elementos diferenciables. Para la comparación de las muestras se han tenido en cuenta varios parámetros texturales (tamaño de grano del desgrasante, relación pasta:desgrasante) y composicionales de las muestras (mineralogía y proporción relativa de esta en el desgrasante, grado de anisotropía de la pasta, etc.), mediante los cuales se ha realizado una discriminación hasta poder realizar grupos de muestras con las mismas características. La adscripción geográfica de las muestras se ha efectuado inicialmente mediante la comparación de su mineralogía con la que se puede encontrar en las Islas Canarias, y en segundo lugar con los resultados del amplio análisis petrológico efectuado en la colonia fenicia de La Fonteta (Alicante), sitio donde se han analizado más de cien fragmentos cerámicos mediante la realización de láminas delgadas y la observación de sus componentes minerales en el microscopio petrográfico ${ }^{7}$.

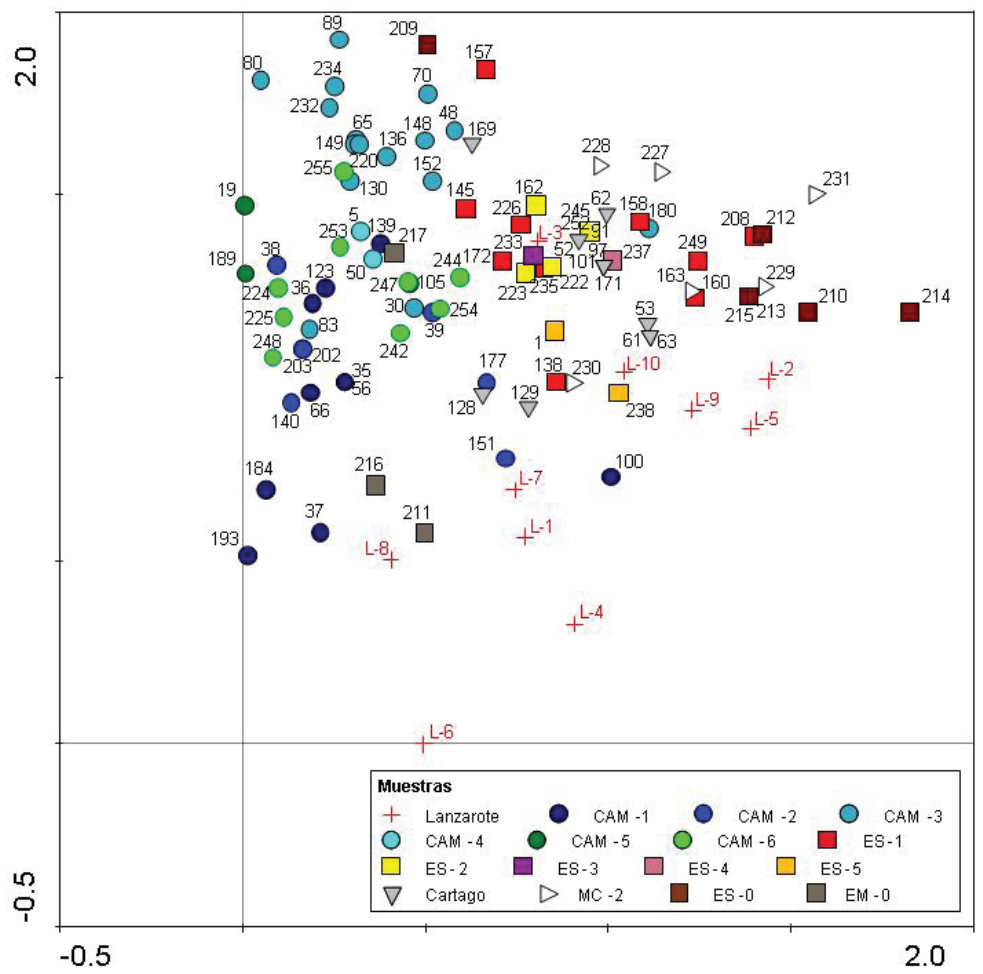

Cuadro no 1: Buenavista. Análisis de Correspondencia Corregido

\footnotetext{
${ }^{7}$ Un procedimiento que permite una primera aproximación a los diagnósticos basados en el análisis de los componentes principales de las rocas y minerales que conforman el desgrasante de las cerámicas. En estos casos se trata de una aproximación, ya que, con las analíticas disponibles una adscripción absolutamente fiable a un determinado lugar es dificultosa dada la repetitividad mineralógica que se produce tanto en Canarias como en las áreas litorales de la cuenca mediterránea, donde la composición geológica y mineralógica es bastante homogénea.
} 
Finalmente, Antonio Rodríguez Rodríguez y Juan Luis Mora Hernández de la Universidad de La Laguna (Departamento de Edafología y Geología. Facultad de Biología) estudiaron las composiciones y efectuaron el Análisis de Correspondencia Corregido (DCA, traducción de Detrended Correspondence Analysis, normalmente abreviado DCA), el cual, al igual que el también muy conocido PCA (Análisis de Componentes Principales), se emplea para ordenar conjuntos de observaciones de manera que se evidencien las tendencias o patrones existentes en los mismos. Para ello se realizan una serie de análisis factoriales que reducen la información recogida en la tabla de datos a unas pocas variables de síntesis, los "ejes", que explican por sí solos una fracción importante de la variación global del sistema. El resultado toma la forma de un diagrama bidimensional (cuadro $\mathrm{n}^{\mathrm{o}} 1$ ), donde se representan los valores de los ejes para cada observación, de tal modo que las observaciones similares se sitúan próximas entre sí y las dispares, separadas. El uso de una u otra técnica de ordenación depende sobre todo de la naturaleza de los datos. En nuestro caso, al tratarse de datos semicuantitativos, el DCA es una técnica adecuada (Hill y Gauch Jr., 1980).

\subsection{Identificación de la procedencia de las cerámicas modeladas a torno}

Las Islas Canarias presentan una gran complejidad en su génesis magmática, dado que los magmas que conformaron las rocas aflorantes proceden de mezclas de reservorios. Desde el punto de vista geoquímico, las rocas volcánicas de las Islas Canarias pertenecen a la serie ígnea alcalina, en este caso asociada a volcanismo de intraplaca. Esta serie ígnea está formada por una secuencia de rocas cuya composición evoluciona desde términos indiferenciados, representados por basaltos, términos intermedios, representados por traquibasaltos y finalmente, términos más diferenciados o evolucionados, representados por traquitas y fonolitas (Aparicio et alii, 2003). De las muestras estudiadas, las número 3, 6, 9 y 10 son las que presentan fragmentos de rocas volcánicas; además la muestra 5 presenta minerales típicos de regiones volcánicas.

La muestra 3 presenta un $75 \%$ de su desgrasante constituido por fragmentos de rocas volcánicas procedentes de la erupción subaérea de un magma altamente alcalino, con fenocristales de nefelina (feldespatoide), augita y olivino, en una matriz vítrea con abundantes vacuolas y microcristales aciculares de rutilo y en algunos casos también microcristales de plagioclasa. La matriz presenta abundantes vacuolas. La presencia de feldespatoides sugiere una lava evolucionada tipo fonolita tefrítica. La muestra 6 presenta fragmentos de roca volcánica menos evolucionada que los de la muestra 3 (Rodríguez et alii, 2008). Se trata de roca volcánica procedente de una erupción subaérea, de textura porfídica, con fenocristales de olivino y plagioclasa, en una matriz vítrea con microcristales de plagioclasa. En algunos casos la matriz presenta vacuolas esféricas, indicando una rápida desgasificación del magma. Podría clasificarse como un basalto plagioclásico; la proporción de desgrasante añadido de origen volcánico en esta muestra no es alta (menos del 10\%), lo cual no permite atribuir con certeza el origen de la muestra a las Islas Canarias.

Las muestras 9 y 10, prácticamente idénticas, presentan fragmentos volcánicos de rocas de textura porfídica, con fenocristales de olivino en una matriz vítrea con va- 
cuolas de desgasificación. Sin embargo, los fragmentos encontrados son muy escasos (proporción inferior al 1\% del volumen de la muestra), lo que prácticamente descarta que proceda de las Islas Canarias, ya que las arenas que proceden de ese archipiélago son casi exclusivamente de origen volcánico. Lo mismo sucede con la muestra 5, muy similar a las muestras 9 y 10 , en la que encontramos, en proporciones inferiores al $1 \%$, cristales de analcima, mineral que aparece como mineral primario de rocas ígneas alcalinas como el basalto rico en sodio o la sienita, o rellenando cavidades de estas rocas en procesos hidrotermales. La baja concentración de material de origen ígneo imposibilita la adscripción de la muestra a las Islas Canarias.

El resto de las muestras (números 1, 2, 4, 5 y 7) no presentan materiales volcánicos, lo que descarta que provengan de las Islas Canarias donde las arenas disponibles presentan una alta proporción de materiales de origen ígneo en su composición, salvo en contados casos en que provienen de sedimentos marinos.

En suma, la identificación de la procedencia de las muestras se ha discutido basándose en la mineralogía del desgrasante añadido a la pasta durante la elaboración de la cerámica. Dado que la mineralogía propia de las regiones volcánicas no es exclusiva de éstas, sino que se repite en muchas de ellas, unido al hecho de que se trata de cerámicas modeladas a torno, una tecnología implantada en Canarias con posterioridad al siglo XV d.C., certifica que estamos ante piezas cerámicas importadas de otros lugares con volcanismo similar al que acontece en las Islas Canarias.

Por su parte, el Análisis de Correspondencias Corregido nos indica que las muestras se caracterizan, de una manera general, por su riqueza en feldespato alcalino, plagioclasa, piroxeno y olivino, y la ausencia de otros minerales frecuentes en las cerámicas como zircón, chamota, distena o micaesquisto. Por tanto constituyen, desde el punto de vista mineralógico, un grupo de cerámicas relativamente homogéneo que, comparado con los grupos considerados por los estudios de caracterización cerámica efectuados en la colonia fenicia de La Fonteta (Alicante) (González Prats, 2008), pertenecientes a diferentes talleres de las colonias fenicias meridionales mediterráneas, presentan notables diferencias con respecto a los grupos CAM-3, CAM-4, CAM-5 y CAM-6. Por el contrario, son semejantes a los grupos CAM-1, CAM-2, Cartago, EM-0, ES-1, ES-5 y MC-2, mostrando una afinidad intermedia con los grupos ES-2, ES-3 y ES-4.

De una manera más concreta y tomando como referencia el Análisis de Correspondencia Corregido se deduce que las muestras cerámicas analizadas de Buenavista, de una forma individualizada, se asemejan en mayor medida con:

- Muestra $n^{\circ} 1$ : Como ya vimos, pertenece, junto con la muestra $n^{\circ} 7$, a un mismo grupo en base a las características de su pasta. En relación con La Fonteta el grupo más próximo es el CAM-2, producción reservada a ánforas con engobe blanquecino identificada en Fonteta III, IV y VI, aunque también se aproxima al grupo CAM-1 el cual incorpora las cerámicas más características y reconocibles de los talleres fenicios de la Costa Andaluza Mediterránea -CAM-, identificadas en Fonteta III, IV y VI.

- Muestra ${ }^{\circ}$ 2: Por la composición de la pasta pertenece, junto con las muestras $\mathrm{n}^{\mathrm{o}} 5,9$ y 10, a un mismo grupo. En relación con La Fonteta está próxima al grupo ES-0 (Elementos Sedimentarios), el cual se corresponde con la fase arcaica de la 
colonia fenicia (Fonteta II), y también a los grupos ES-5 (identificado en Fonteta V/VI) y Cartago (ánforas con las características texturales de las producciones de Cartago identificadas en Fonteta I/II, II, III, IV y VI).

- Muestra $n^{0}$ 3: Pequeño cuenco cuya pasta presenta grandes similitudes con el grupo ES-3 (identificado en Fonteta VI), estando también muy próximo a los grupos ES-1 (identificado con Fonteta II, III, IV y VI), ES-5 y Cartago.

- Muestra ${ }^{\circ}$ 4: Cerámica tardía (vidriada), confirmando su procedencia del estrato superficial.

- Muestra $\mathrm{n}^{0}$ 5: Por la composición de la pasta pertenece, junto con las muestras $\mathrm{n}^{\circ} 2,9$ y 10 , a un mismo grupo. En relación con La Fonteta está próxima al grupo ES-0, aunque también está cercana a los grupos ES-5 y Cartago.

- Muestra $n^{\circ}$ 6: No está próxima a ningún grupo en concreto, el más cercano sería el CAM-1.

- Muestra $\mathrm{n}^{0}$ 7: Por la composición de la pasta presenta similitudes con la muestra $n^{\circ} 1$. En relación con La Fonteta está muy próxima al grupo CAM-2, aunque también se aproxima al grupo CAM-1.

- Muestra $n^{\circ} 8$ : Fragmento perteneciente a la base de un ánfora romana localizada en aguas de Lanzarote; se introdujo en la muestra como control para conocer las similitudes de las pastas empleadas en época romana y fenicio-púnica.

- Muestra $n^{\circ}$ 9: Por la composición de la pasta pertenece, junto con las muestras $\mathrm{n}^{\mathrm{o}} 2,5$ y 10, a un mismo grupo. En relación con La Fonteta está próxima al grupo ES-5, pero también a los grupos ES-0 y Cartago.

- Muestra $\mathrm{n}^{\circ}$ 10: Por la composición de la pasta pertenece, junto con las muestras $\mathrm{n}^{\circ} 2,5$ y 9, a un mismo grupo. En relación con La Fonteta está muy próxima al grupo ES-5, presentando también grandes similitudes con los grupos Cartago, MC-2 (Mediterráneo Central) (identificado en Fonteta II) y ES-1.

En relación con la secuencia estratigráfica, las muestras procedentes del estrato II $\left(\mathrm{n}^{\mathrm{o}}\right.$ 1, 6, 9 y 10), el más antiguo de Buenavista, en atención a los grupos de pastas a que pertenecen (CAM 1, CAM 2, ES-0, ES-5 y Cartago) también se corresponden con las fases más antiguas de La Fonteta (I/II, II, III, IV, V/VI y VI). Algo similar ocurre con las muestras recuperadas de la base del estrato I de Buenavista $\left(n^{\circ} 2,3,5\right.$ y 7), las cuales también están atestiguadas desde las fases más antiguas de La Fonteta (I/II, II, III, IV, V/VI y VI). Por el contrario, la muestra $\mathrm{n}^{\mathrm{o}} 4$ corresponde con una cerámica tardía, posterior al siglo XIX, lo que concuerda con su procedencia estratigráfica del estrato superficial de Buenavista.

\subsection{Las cerámicas modeladas a mano}

En Buenavista las cerámicas modeladas a mano son mayoritarias. El análisis diacrónico de sus características morfotécnicas determinan la aparición de diferencias, que se concentran principalmente a nivel de la morfología y de la presencia/ausencia de motivos decorativos. 

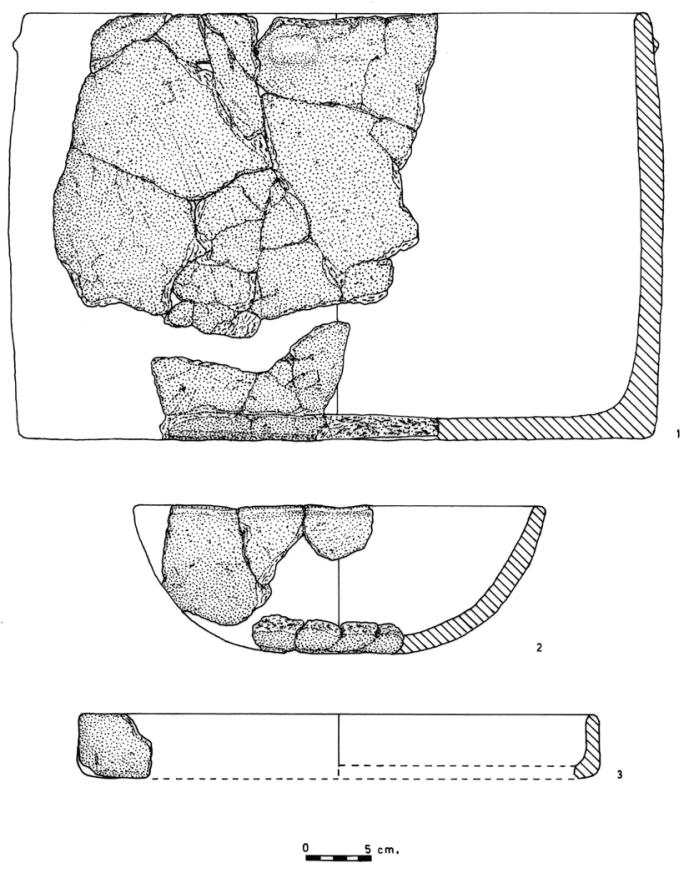

Fig. 4: Buenavista. Recipientes cerámicos modelados a mano localizados en el nivel de abandono del estrato II

Las cerámicas del estrato II (Fig. 4), aquellas que marcan la primera presencia de esas producciones en el lugar, se caracterizan en general por unos recipientes con paredes finas o medias, y en menor medida gruesas, este último es el caso de varios de los vasos localizados en el habitáculo $\mathrm{n}^{\circ} 1$, lo que está en relación con el gran tamaño de esas piezas. Son recipientes con formas de tendencia cilíndrica con base plana y asas de lengüeta, tendencia troncocónica invertida y base plana y tendencia al casquete esférico, base plana y amplio diámetro de boca. Además de los anteriores recipientes, caracterizados por unas dimensiones muy superiores a la media de los restantes vasos localizados en el yacimiento, también se recuperaron otros tipos con formas de tendencia al casquete esférico, en algún caso con la base plana, de tendencia semiesférica y paredes cortas, de tendencia cilíndrica y base plana, de tendencia cilíndrica con paredes rectas y el arranque de un asa de lengüeta y de tendencia troncocónica. Este último es un grupo de vasijas de cocina con capacidad pequeña o media entre las cuales destaca un recipiente de tendencia al casquete esférico elaborado con una pasta cerámica de gran calidad con la superficie exterior de color negro homogéneo. La lista de formas se completa con dos micro-recipientes, en un caso de tendencia al casquete esférico y en el otro de tendencia esférica.

En general, las cerámicas del estrato II se caracterizan a nivel morfotécnico por poseer paredes con espesores finos o medios, y sólo ocasionalmente gruesos, con labios planos o redondeados. Muchas bases son planas, mientras que los elementos 
de prehensión están representados por asas de mamelón y de lengüeta con impresión central. Resulta significativo el predominio casi absoluto de los recipientes sin decorar; no obstante, hay algunos motivos localizados en los labios y realizados con trazos lineales incisos o transversales impresos.

En el estrato I (Fig. 5) las cerámicas modeladas a mano corresponden en la mayor parte de los casos a vasijas de cocina con capacidad pequeña o media y formas de tendencia al casquete esférico, en un caso con el labio plano-redondeado y engrosado al exterior, de tendencia semiesférica y labio plano engrosado al exterior, posible tendencia esférica con cuello corto cilíndrico correspondiente a una pequeña olla de cocina, y vasos con forma de tendencia cilíndrica. Junto a las anteriores también se registra algún ejemplo de vaso de morfología compuesta, donde la base es de tendencia al casquete esférico y el cuerpo de tendencia troncocónica, con el labio plano y decorado con impresiones. Los vasos de pequeñas dimensiones son relativamente frecuentes, con formas de tendencia al casquete esférico o de tendencia esférica; en este último grupo se incluyen varios micro-recipientes con formas de tendencia al casquete esférico, tendencia cilíndrica o tendencia troncocónica invertida y base plana.
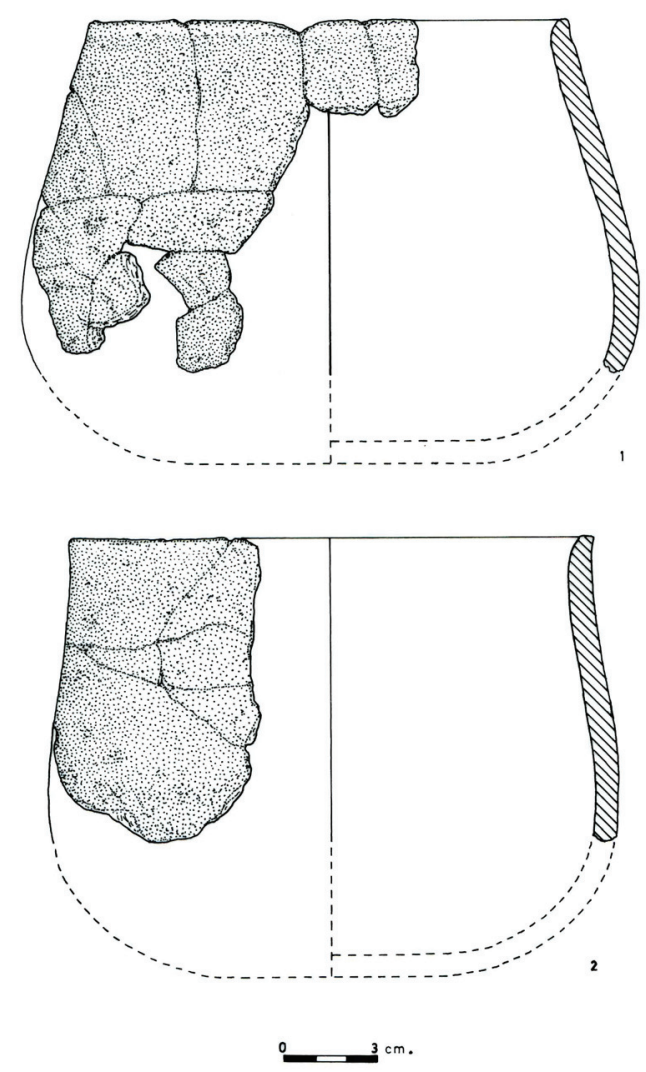

Fig. 5: Buenavista. Recipientes cerámicos modelados a mano del estrato I 
Como norma general, los recipientes cerámicos del estrato I presentan paredes altas, con grosores medios y ocasionalmente grueso, labios planos o redondeados, ocasionalmente engrosados al exterior o decorados con impresiones finas o pequeñas impresiones transversales de tendencia circular o incisiones. Hay bordes rectos con labios planos, ocasionalmente decorados con una ancha acanaladura longitudinal. Los cuellos son cortos y responden a formas de tendencia troncocónica invertida o de tendencia cilíndrica. También hay varios fragmentos de bases planas con paredes de espesor medio o grueso, en algún caso con un engrosamiento que recorre el borde externo. Las decoraciones se localizan en las superficies exteriores, donde se han desarrollado motivos simples, conformados por trazos incisos lineales o en zig-zag.

En conjunto, los artefactos cerámicos recuperados en el estrato I no suponen una ruptura drástica con la tradición tecnológica representada por el estrato II si bien hay cambios, como es una mayor presencia de vasos cerámicos decorados con motivos geométricos elaborados con incisiones o impresiones.

El estrato superficial (Fig. 6), como ya vimos, posee escaso interés desde la perspectiva arqueológica, de hecho el registro material está determinado por su extremada pobreza, toda vez que está constituido sólo por algunos elementos poco significativos, y en general de cronología muy tardía. En él pueden encontrarse algunos elementos materiales pertenecientes al estrato inferior, el estrato I, llegados allí como resultado de las remociones debidas a la acción del arado.
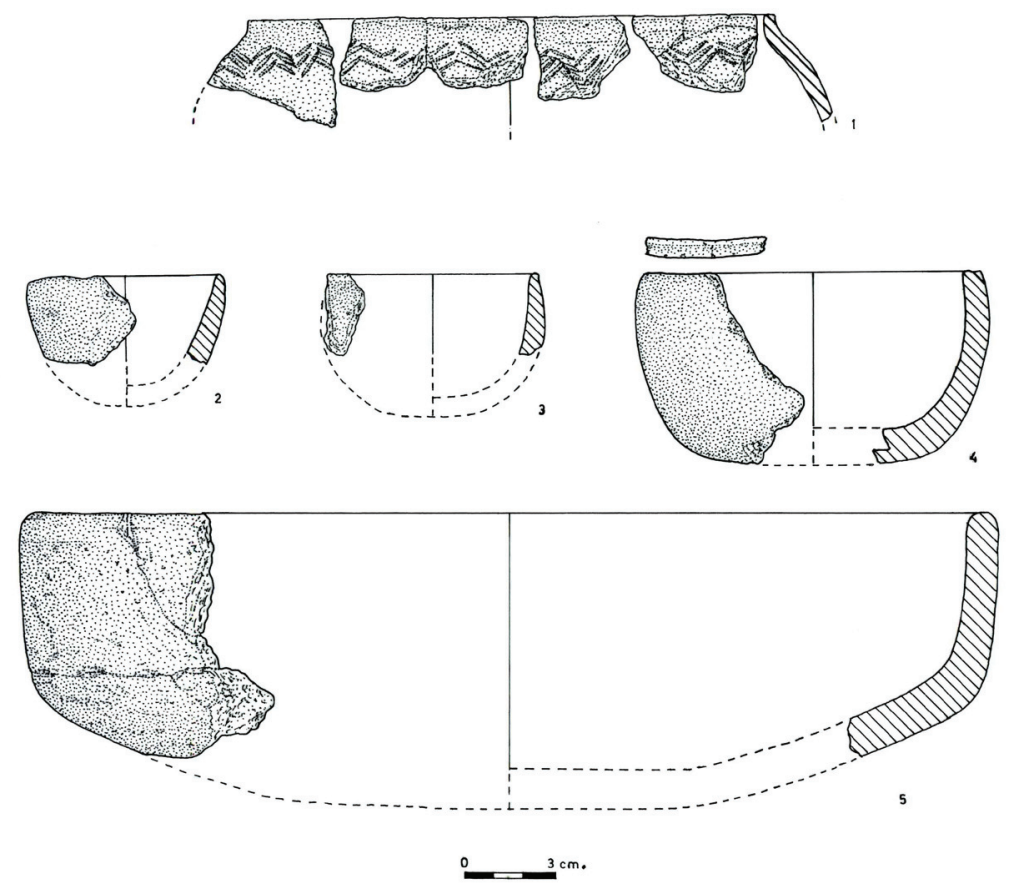

Fig. 6. Buenavista. Recipientes cerámicos modelados a mano del estrato superficial 


\section{Las cronologías}

En otro lugar (Atoche, 2008 y 2009) ya señalábamos la necesidad que existía, en el ámbito de las investigaciones centradas en la Protohistoria canaria, de ampliar y diversificar la muestra de dataciones absolutas disponibles para la isla de Lanzarote. En la actualidad hemos conseguido superar esa deficiencia, contando con fechas inmersas en series amplias procedentes de yacimientos con potentes secuencias estratigráficas (El Bebedero, Caldereta de Tinache,...), las cuales reflejan el devenir histórico de la isla desde el siglo I a.C. hasta los albores de la conquista normandocastellana, en el siglo XIV d.C., fijando la más antigua ocupación de Lanzarote en el siglo I a/d.C. (0 BC/AD cal.) (GrN-19194). Junto a las anteriores, en la cercana isla de La Graciosa el yacimiento de El Descubrimiento aportó dos dataciones obtenidas por termoluminiscencia que colocan el inicio de la presencia humana allí en torno a los comienzos del primer milenio a.C. (1096 \pm 278 a.C. y $950 \pm 277$ a.C.) (González y Arco, 2007: 206). Como vemos, entre el grupo de dataciones de Lanzarote y el de La Graciosa se abre un amplio espacio temporal que resulta necesario documentar arqueológicamente, una circunstancia que la serie de dataciones $\mathrm{C}^{14}$ obtenidas en Buenavista $^{8}$ ha venido en parte a solucionar $\left(\right.$ Cuadro $\left.n^{\circ} 2\right)$.

\begin{tabular}{|c|c|c|c|c|c|c|c|}
\hline 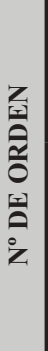 & 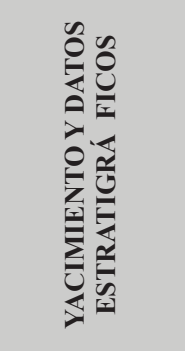 & 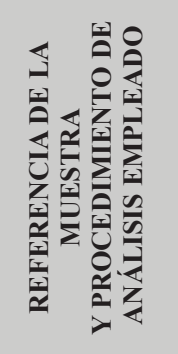 & 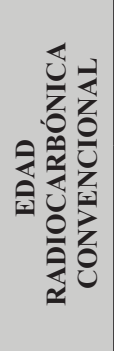 & $\begin{array}{c}0 \\
0 \\
12 \\
1 \\
1 \\
1\end{array}$ & $\begin{array}{l}\text { INTERCEPTACIÓN } \\
\text { DE LA EDAD } \\
\text { RADIOCARBÓNICA } \\
\text { CON LA CURVA DE } \\
\text { CALIBRACIÓN }\end{array}$ & 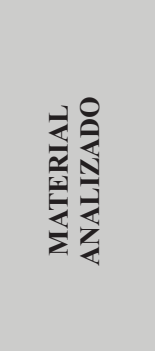 & 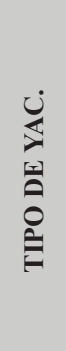 \\
\hline \multirow[t]{2}{*}{1} & \multirow{2}{*}{$\begin{array}{c}\text { Buenavista } 06 \\
\text { B6/II-1 }\end{array}$} & \multirow{2}{*}{$\begin{array}{c}\text { Beta-230.885 } \\
\text { AMS }\end{array}$} & \multirow{2}{*}{$2280 \mathrm{BP}$} & \multirow[t]{2}{*}{40} & $\begin{array}{l}400 \text { a } 350 \text { BC cal- } \\
300 \text { a } 210 \text { BC cal. }\end{array}$ & \multirow{2}{*}{$\begin{array}{l}\text { sedimento } \\
\text { orgánico }\end{array}$} & \multirow[t]{2}{*}{ A.S. } \\
\hline & & & & & 380 BC cal. & & \\
\hline \multirow[t]{2}{*}{2} & \multirow{2}{*}{$\begin{array}{c}\text { Buenavista } 07 \\
\text { E4/II-1 }\end{array}$} & \multirow{2}{*}{$\begin{array}{c}\text { Beta-237.340 } \\
\text { AMS }\end{array}$} & \multirow[t]{2}{*}{$2180 \mathrm{BP}$} & \multirow[t]{2}{*}{40} & $\begin{array}{l}370 \text { a } 150 \text { BC cal.- } \\
140 \text { a } 110 \text { BC cal. }\end{array}$ & \multirow{2}{*}{$\begin{array}{l}\text { sedimento } \\
\text { orgánico }\end{array}$} & \multirow[t]{2}{*}{ A.S. } \\
\hline & & & & & 330 BC cal. & & \\
\hline \multirow{2}{*}{3} & \multirow{2}{*}{$\begin{array}{l}\text { Buenavista } 07 \\
\text { F4/II-3 Base }\end{array}$} & \multirow{2}{*}{$\begin{array}{c}\text { Beta-237.341 } \\
\text { AMS }\end{array}$} & \multirow{2}{*}{$2450 \mathrm{BP}$} & \multirow{2}{*}{50} & 780 a 400 BC cal. & \multirow{2}{*}{$\begin{array}{l}\text { sedimento } \\
\text { orgánico }\end{array}$} & \multirow{2}{*}{ A.S. } \\
\hline & & & & & 530 BC cal. & & \\
\hline 4 & $\begin{array}{c}\text { Buenavista } 08 \\
\text { B10/I-1 }\end{array}$ & $\begin{array}{l}\text { Beta-251.320 } \\
\text { AMS }\end{array}$ & $1780 \mathrm{BP}$ & 40 & $\begin{array}{l}130 \text { a } 350 \text { AD cal. } \\
240 \text { AD cal. }\end{array}$ & $\begin{array}{c}\text { huesos de } \\
\text { ovicápridos }\end{array}$ & A.S. \\
\hline \multirow{2}{*}{5} & \multirow{2}{*}{$\begin{array}{c}\text { Buenavista } 08 \\
\text { D9/I-2 }\end{array}$} & \multirow{2}{*}{$\begin{array}{c}\text { Beta-251.321 } \\
\text { AMS }\end{array}$} & \multirow{2}{*}{$2030 \mathrm{BP}$} & \multirow{2}{*}{40} & 160 BC a 60 AD cal. & \multirow{2}{*}{$\begin{array}{l}\text { sedimento } \\
\text { orgánico }\end{array}$} & \multirow{2}{*}{ A.S. } \\
\hline & & & & & 40 BC cal. & & \\
\hline
\end{tabular}

8 Los análisis fueron efectuados en Beta Analytic Radiocarbon Dating Laboratory (Florida), evaluándose las fechas obtenidas calibradas y sometidas a índices de desviación homogenizados. 


\begin{tabular}{|c|c|c|c|c|c|c|c|}
\hline \multirow[t]{2}{*}{6} & \multirow{2}{*}{$\begin{array}{c}\text { Buenavista } 08 \\
\text { D9/II-3 Base } \\
\text { Base del muro }\end{array}$} & \multirow{2}{*}{$\begin{array}{c}\text { Beta-251.322 } \\
\text { AMS }\end{array}$} & \multirow[t]{2}{*}{2810 BP } & \multirow[t]{2}{*}{40} & $\begin{array}{l}1050 \text { a } 890 \text { BC cal. } \\
870 \text { a } 850 \text { BC cal. }\end{array}$ & \multirow[t]{2}{*}{ carbón } & \multirow[t]{2}{*}{ A.S. } \\
\hline & & & & & 960 BC cal. & & \\
\hline \multirow[t]{2}{*}{7} & \multirow[t]{2}{*}{$\begin{array}{c}\text { Buenavista } 08 \\
\text { H2/I-2 Base }\end{array}$} & \multirow[t]{2}{*}{$\begin{array}{c}\text { Beta-251.323 } \\
\text { AMS }\end{array}$} & \multirow[t]{2}{*}{2140 BP } & \multirow[t]{2}{*}{40} & $\begin{array}{l}360 \text { a } 290 \text { BC cal. } \\
240 \text { a } 50 \text { BC cal. }\end{array}$ & \multirow[t]{2}{*}{$\begin{array}{c}\text { sedimento } \\
\text { orgánico }\end{array}$} & \multirow[t]{2}{*}{ A.S. } \\
\hline & & & & & 180 BC cal. & & \\
\hline
\end{tabular}

Cuadro no 2: Buenavista. Datos generales de la serie de dataciones C14 obtenidas

Los datos cronológicos proporcionados por Buenavista señalan que la estructura se construyó en la segunda mitad del siglo X a.C., ocupándose a partir de entonces el asentamiento hasta la segunda mitad del siglo IV a.C., fecha en la que la estructura fue abandonada; el lugar será de nuevo visitado a partir de la primera mitad del siglo II a.C. y hasta mediados del siglo III d.C., una etapa cuyo desarrollo final coincide con un momento que, a nivel de la Protohistoria insular, se corresponde con un período de expansión en la ocupación del territorio, como atestiguan los numerosos asentamientos pertenecientes a esa etapa distribuidos por la totalidad de la superficie de la isla. Para entonces, la estructura llevaba ya varios siglos fuera de uso, de ahí que en realidad lo que se reocupa es el espacio donde se hallaba el antiguo asentamiento y no el asentamiento en sí mismo. De hecho, comparada con la primera ocupación esta segunda fue de menor intensidad, probablemente estacional, tal y como lo demuestran los escasos registros materiales presentes que, en el caso de los elementos cerámicos se caracterizan por presentar una gran fragmentación. La estacionalidad de esta segunda ocupación de Buenavista debió estar directamente relacionada con el pastoreo de ovicápridos y el aprovechamiento por parte del ganado del depósito de agua estacional que aún en la actualidad suele conformarse durante la estación de las lluvias en el extremo occidental de la hoya.

\section{Conclusiones}

Resulta patente que la presencia fenicio-púnica en Lanzarote queda atestiguada no sólo por la propia morfología de la estructura descubierta en Buenavista sino también por una parte significativa de los registros materiales recuperados (ánforas y otros recipientes modelados a torno, elementos metálicos y vítreo,...).

Por lo que a la estructura se refiere ésta constituye, tanto desde la perspectiva morfológica (planta rectangular con muros de piedra, suelo de arcilla rojiza batida por debajo del nivel exterior, banco adosado al muro,...), como desde el punto de vista de las técnicas utilizadas para levantar muros y tabiques, un sitio asimilable a los asentamientos rurales púnicos mediterráneos. Pero además, hay que tener en cuenta la presencia desde el estrato más profundo de cerámicas modeladas a torno, cuya caracterización petrográfica de las pastas pone de manifiesto las grandes semejanzas que presentan con varios de los grupos cerámicos definidos en la colonia feniciopúnica de La Fonteta, una circunstancia que no sólo confirma la procedencia feniciopúnica de las muestras de Buenavista sino que también atestigua su antigüedad, en correspondencia con la que inicialmente proponían las dataciones radiocarbónicas 
del yacimiento lanzaroteño, en especial para las muestras de los grupos CAM-1 ( $\mathrm{n}^{\mathrm{o}}$ $1,6,7)$ y ES-5 $\left(n^{\circ} 2,5,9\right.$ y 10$)$.

En ese sentido, las dataciones radiométricas señalan que la primera presencia humana en Lanzarote se produjo en el siglo X a.C., momento en el que la isla sería frecuentada por marinos fenicio-púnicos (Bartoloni, 1990; Wagner, 1995) quienes llevarían a cabo una primera colonización con un contingente de población afín, fenómeno del que el sitio de Buenavista constituye un ejemplo del patrón locacional puesto en práctica. A partir del siglo VI a.C. el proceso colonizador insular debió reforzarse coincidiendo con la expansión de Cartago (Fantar, 1988; Frutos Reyes, 1991; Aubet, 1994), ciudad que en esos momentos se lanza al dominio efectivo de amplios territorios de África y al cierre del Estrecho de Gibraltar a otros navegantes (López Castro, 1992). En consecuencia, en Buenavista nos hallamos ante una comunidad muy antigua que posee evidentes elementos procedentes de la cultura fenicio-púnica del Mediterráneo occidental, los cuales sabemos que perdurarán con posterioridad en el ámbito de las poblaciones insulares determinando aspectos tan fundamentales como los ritos funerarios o las creencias religiosas (Atoche y Ramírez, 2008).

La presencia fenicio-púnica más allá de las Columnas de Hércules (López Pardo, 1991), en zonas de interés económico para Gadir y Lixus, pudo llevarse a cabo, como asegura F. López Pardo (1990), para defender los intereses de los enclaves del Círculo del Estrecho, o bien para usurpar territorios y hacerse con un lugar en el control de las riquezas al margen de dichos enclaves. Sea como fuera, los navegantes semitas recorrieron el occidente africano con unos fines concretos; sus travesías estaban motivadas por factores económicos y en esa labor de rastreo no pudo pasar desapercibido el archipiélago canario, que habría sido visitado desde fechas tempranas en busca de fondeaderos y recursos de todo tipo, algunos escasos o inexistentes en el litoral africano, lo que haría que su colonización tuviera una importancia geoestratégica y económica de primer orden.

\section{Bibliografía}

APARICIO, A., HERNÁN, F., CUBAS, C.R. y ARAÑA, V. (2003): "Fuentes mantélicas y evolución del volcanismo canario", Estudios Geológicos, 59, 5-13.

ATOCHE, P., RODRÍGUEZ, Ma'.D. y RAMÍREZ, Mª.A. (1989): El yacimiento arqueológico de 'El Bebedero'(Teguise, Lanzarote). Resultados de la primera campaña de excavaciones, Universidad de La Laguna, Serie Investigación. Madrid.

ATOCHE, P. (1993): "El poblamiento prehistórico de Lanzarote. Aproximación a un modelo insular de ocupación del territorio", Tabona, VIII, 77-92.

ATOCHE, P., PAZ, J.A., RAMÍREZ, Mª.A. y ORTIZ, Mª.E. (1995): Evidencias arqueológicas del mundo romano en Lanzarote (Islas Canarias), Col. Rubicón, 3. Arrecife.

ATOCHE, P. (1996): “Aproximación al estado actual del Patrimonio Arqueológico de Lanzarote: la Carta Arqueológica", Tabona, IX, 9-44. 
ATOCHE, P. y MARTÍN, J. (1999): “Canarias en la expansión fenicio-púnica por el África atlántica”, II Congreso de Arqueología Peninsular, III, 485-500.

ATOCHE, P. (2003): "Fenómenos de intensificación económica y degradación medioambiental en la Protohistoria canaria", Zephyrus, LVI, 183-206.

ATOCHE, P., RAMÍREZ, Ma.A., PÉREZ, S. y TORRES, J.D. (2007): “Primera campaña de excavaciones arqueológicas en el yacimiento de la Caldereta de Tinache (Tinajo, Lanzarote)", Canarias Arqueológica (Arqueología/Bioantropología), 15, $13-46$.

ATOCHE, P., RAMÍREZ, Ma.A. (2008): "Manifestaciones de la religiosidad mediterránea en la Protohistoria canaria (circa s. X a.n.e. al s. XV d.ne.)", Gerión, 26, 183-202.

ATOCHE, P. (2008): "Las culturas protohistóricas canarias en el contexto del desarrollo cultural mediterráneo: propuesta de fasificación", en R. González - F. López - V. Peña (eds.), Los Fenicios y el Atlántico, Centro de Estudios Fenicios y Púnicos, IV Coloquio del CEFYP, 317-344.

ATOCHE, P. (2009): "Estratigrafías, cronologías absolutas y periodización cultural de la Protohistoria de Lanzarote", Zephyrus, LXIII, 105-134.

ATOCHE, P., RAMÍREZ, Ma .A., TORRES, J.D. y PÉREZ, S. (2009): “Excavaciones arqueológicas en el yacimiento de Buenavista (Tiagua, Lanzarote): primera campaña, 2006", Canarias Arqueológica (Arqueología/Bioantropología), 17, 9-51.

AUBET, Ma.E. (1994): Tiro y las colonias fenicias de Occidente, Crítica. Barcelona.

BALBÍN, R. de, BUENO, P., GONZÁLEZ, R. y ARCO, Ma .C. (1995): "Datos sobre la colonización púnica de las Islas Canarias", Eres (Arqueología), 6 (1), 7-28.

BARTOLONI, P. (1990): “Aspetti precoloniali della colonizzacione fenicia in Occidente", Rivista di Studi Fenici, XVIII, 157-167.

CRIADO, C. y ATOCHE, P. (2003): "Estudio geoarqueológico del yacimiento de El Bebedero (siglos I a.C. a XIV d.C., Lanzarote, Islas Canarias)", Cuaternario y Geomorfología, 17 (1-2), 91-104.

DÍES, E. y MATAMOROS, C. (1991): “Introducción al estudio de la arquitectura púnica de Ibiza", Atti del II Congresso Internazionale di Studi Fenici e Punici, 2, 817-824.

FANTAR, M. (1988): "Carthage: archetypes et specificité. Carthage et son territoire dans l'antiquité", Actes du IV Colloque International sur l'Histoire et l'Archéologie de l'Afrique du Nord, I, 53-65.

FRUTOS REYES, G. (1991): Cartago y la politica colonial. Los casos norteafricano e hispano, Gráficas Sol. Écija.

GONZÁLEZ, R. y ARCO, Mª.C. (2007): Los enamorados de la Osa Menor, Canarias Arqueológica, Monografías, 1. OAMC. Santa Cruz de Tenerife. 
GONZÁLEZ, R. y ARCO, Ma.C. (2009): "Navegaciones exploratorias en Canarias a finales del II milenio a.C. e inicios del primero. El cordón litoral de La Graciosa (Lanzarote)", Canarias Arqueológica (Arqueología/Bioantropología), 17 (anejo I), pp. 9-80.

GONZÁLEZ PRATS, A. (2008): “Avance de los análisis de caracterización de las cerámicas de La Fonteta", Cuadernos de Arqueología Mediterránea, 18, 53-79.

HERNÁNDEZ, L., GONZÁLEZ M.C., JIMÉNEZ, C., ORTEGA, M.J., PADRÓN, P., RODRÍGUEZ, A., TORRES, J.M. y VARGAS, G.E. (1991): "Suelos de la isla de Lanzarote. Características generales", XVIII Reunión Nacional de Suelos, 311-330.

HILL, M.O. y GAUCH jr., H.G. (1980): "Detrended Correspondence Analysis, an improved ordenation technique", Vegetatio, 42, 47-58.

LÓPEZ CASTRO, J.L. (1992): "Los libiofenicios: una colonización agrícola cartaginesa en el sur de la Península Ibérica", Rivista di Studi Fenici, XX (1), 47-65.

LÓPEZ, F. y MEDEROS, A. (2008): La factoría fenicia de la isla de Mogador y los pueblos del Atlas, Canarias Arqueológica, monografías, 3, OAMC. Santa Cruz de Tenerife.

LÓPEZ PARDO, F. (1990): "Sobre la expansión fenicio-púnica en Marruecos. Algunas precisiones a la documentación arqueológica", Archivo Español de Arqueología, 67, 7-41.

LÓPEZ PARDO, F. (1991): "El Periplo de Hannón y la expansión cartaginesa en el África occidental", V Jornadas de Arqueología Fenicio-Púnica, 59-70.

MARCOS, C (1986. Capacidad de uso de los suelos de la isla de Lanzarote, Consejería de Obras Públicas, Gobierno de Canarias.

MEDEROS, A. y ESCRIBANO, G. (2002): Fenicios, púnicos y romanos. Descubrimiento y poblamiento de las Islas Canarias. Estudios Prehispánicos, 11. DGPH. Madrid.

MUNSELL, A.H. (1975): Munsell Soil Color Charts, Baltimore.

RODRÍGUEZ, E., CARRACEDO, J.C., PÉREZ, F.J. y SERGIO, J. (2008): "Rocas volcánicas del Teide", en El volcán Teide. Geología y Volcanología del Teide y las Dorsales, t. 1, cap. 4, 95-144, Ediciones y Producciones Saquiro S.L., VII.

SANTANA, A., ARCOS, T., ATOCHE, P. y MARTÍN, J. (2002): El conocimiento geográfico de la costa noroccidental de África en Plinio: la posición de las Canarias, Georg Olms Verlag, Spudasmata, Band 88. Hildesheim-Zürich-New York.

WAGNER, C.G. (1995): "Fenicios y autóctonos en Tartessos. Consideraciones sobre las relaciones coloniales y la dinámica de cambio en el suroeste de la Península Ibérica", Trabajos de Prehistoria, 52(1), 109-126. 